\title{
Mujeres, biología, feminismos: un ensayo bibliográfico
}

Women, biology, feminisms: a bibliographical essay

\author{
María Jesús SANTESMASES \\ Instituto de Filosofía-CCHS, CSIC
}

Resumen. En este artículo se repasan algunas de las líneas de investigación más influyentes en el área de los estudios sobre biología y género y libros publicados al respecto por un grupo creciente de autoras. Como es habitual entre los estudios de género, en este caso los referentes a la biología cuentan con estudios sobre investigadoras en el área de la biología, mujeres que participaron activamente en la generación de saberes y prácticas de esta disciplina, por una parte, y con trabajos sobre los sesgos epistémicos de género y sobre el androcentrismo en el conocimiento biológico, por otra. La genealogía se relaciona con la autoridad y ésta con el género como agencia en las ciencias y las experimentaciones contemporáneas.

Palabras clave: mujeres, biología, género, siglo xx, feminismo.

Los estudios feministas sobre biología cuentan con pioneras muy influyentes, procedentes de especialidades biológicas y filosóficas, cuyas propuestas han dotado de contenido a todo un programa de investigación, de práctica analítica y de pensamiento sobre las naturalezas y los sesgos de los saberes que se acumulan sobre ellas. Esas prácticas de las mujeres a la búsqueda de formas de pensar el mundo que pueda situarlas en él, reconocerlas y aceptar sus formas de mirar
Abstract. This paper revises some of the most influential researches on gender and biology and books published by an increasing group of women scholars. As usual in gender studies, those concerning biology refer to those in search of women biologists in history of science, women who actively took part in generating knowledge and practices of the discipline, in one hand, and those on gender-biased and anthropocentric biological knowledge. Genealogy is linked to authority and both with gender as agency on contemporary sciences and experimentations.

Key words: women, biology, gender, $20^{\text {th }}$ century, feminism.

como miradas expertas, de autoridad, ha generado un espacio académico propio. Ese espacio no siempre logra tener un nombre que lo identifique: los estudios feministas en un instituto de filosofía y en uno de historia de la ciencia pueden carecer de departamento propio aunque en otras ocasiones sí lo tengan, como es el caso de los institutos de estudios de las mujeres y feministas que con términos semejantes existen en algunas universidades españolas ${ }^{1}$. 
Los trabajos sobre mujeres y biología tiene dos partes que parecen reforzarse mutuamente. Por un lado están los estudios que recuperan las aportaciones de mujeres a la historia de la biología, que rastrean genealogías de mujeres en la producción de prácticas y de pensamiento biológico. Los estudios feministas se ocupan también de estudiar los sesgos de género del propio conocimiento. Ambos, genealogías y sesgos de género, pueden reforzarse mutuamente, o no hacerlo. En el grupo de especialistas que comparten una cultura sobre el conocimiento experto y sus capacidades para ver el mundo y proponer aproximaciones a él, este refuerzo podría parecer inevitable, hasta obvio. Pero en el conocimiento público y en sus políticas han logrado más influencia la preocupación por la genealogía y el reconocimiento de las funciones sociales, culturales y profesionales que desempeñan y podrían desempeñar las mujeres, que el hecho de que el conocimiento experto pudiera no ser neutral sino aparecer cargado de culturas cuya singularidad y sexismo no serían tan populares.

Es decir, una vez las mujeres se aceptan en las comunidades expertas, una vez hay mujeres catedráticas, profesoras, maestras de escuelas de pensamiento a las que sería costoso ignorar, poner de manifiesto que hay y hubo otras mujeres en la historia del conocimiento que nos preceden a todas, sobre las que se ha estudiado poco y a las que estudios de recuperación histórica parecen haber ignorado puede aceptarse como un primer paso, como una introducción a la epistemología feminista. La autoridad de muchos hombres y las formas sociales que toma y ha tomado la distribución sexual del trabajo pudo haber ocultado a las mujeres en el relato historiográfico y en el análisis de las comunidades expertas, y así parece haber llegado a aceptarse en buena medida también entre nuestros colegas hombres.

\section{Al rastro de las genealogías}

No se trataría sólo de recuperar el género femenino en el habla como forma de hacer visibles a expertas, científicas e investigadoras, profesoras universitarias y profesionales en general, sino a través de los usos del femenino reintegrar la presencia de las mujeres en las narrativas de nuestro tiempo. De esta forma, ese trabajo sistemático que recupera a las mujeres para el relato histórico de las disciplinas biológicas da soporte a esas prácticas socioprofesionales que aspiran a la inclusión de las mujeres en el trabajo y en sus recursos narrativos ${ }^{2}$.

Recuperar las contribuciones de las mujeres al conocimiento biológico da soporte a esas prácticas de inclusión. Desde la compilación de Abir-Am y Outram, Kass-Simon y Farnes, pasando por la revisión tan completa de Margaret Rossiter, los trabajos que han repuesto a las mujeres en la historia de la biología se completan con la presencia de las mujeres en las prácticas de salud y en las investigaciones propias de la medicina experimental $^{3}$. Mujeres en el campo, que estudian animales y plantas, que cultivan cereales y flores, que crían caballos y seleccionan ratones, que observan insectos y elaboran tablas; todas ellas han contribuido a la creación científica y a la difusión de ideas sobre herencia, genética, naturaleza $y$, en general, al saber sobre el funcionamiento del interior de los seres vivos y de las interacciones con su medio.

En medio de la corrección política que estiliza nuestro tiempo, y en sintonía con el recurso retórico del femenino en la vida pública, las muestras de la historiografía, la filosofía y la sociología de las ciencias ofrecen un marco al que las mujeres no han sido ajenas y que justificaría esta inclusión del femenino tanto como una cierta corrección de los discursos públicos y privados. La actividad doméstica 
que se adjudicaba a las mujeres incluía multitud de trabajos de cuidado de la prole y de la familia en general, de mujeres que sanaban a mujeres, parteras que atendían a embarazadas de su entorno, de mujeres que experimentaban en su propia casa ${ }^{4}$. Granjas y cuadras, jardines y ganados han sido atendidos por mujeres.

Como la agricultura, la ganadería y sus prácticas de selección sintonizaron en buena parte con las teorías darwinianas y mendelianas recuperadas, esas comunidades del campo y las industrias de animales y plantas contaban con la participación de las mujeres. Mentar algunos casos aunque apenas fuera para reactivar la memoria colectiva, devuelve a mujeres tales como Judith Blunt Lytton, más conocida como Lady Wentworth, quien está considerada como una de las más significativas personas dedicadas a la cría de caballos de raza árabe por su parte en la conservación de la pureza de los caballos que sus padres habían criado tras comprar una potra en Alepo hacia $1880^{5}$.

Muchas mujeres hicieron trabajos pioneros sobre herencia, sobre genética, sobre fisiología animal y humana, sobre microbiología, sobre nutrición. Entre las genetistas de la primera ola hay, junto a los hombres ilustres tomados como héroes iniciadores, o quizá solo temporalmente ocultas tras ellos por la historiografía hasta hace muy poco, un buen grupo de experimentadoras en el que se encuentran Nettie Stevens en Bryn Mawr, cuyas aportaciones a la biología de los cromosomas sexuales se oscurecían tras el crédito que logró E. B. Wilson; Helen Dean King en el Instituto Wistar, que crió ratas de laboratorio de las que obtuvo información sobre transmisión hereditaria esencial para el posterior desarrollo de la genética animal; $\mathrm{Mu}$ riel Wheldale, entre las colaboradoras de William Bateson en Cambridge, que destaca por sus contribuciones a la genética bioquímica; Elisabeth Schiemann en Berlín quien, además de por sus estudios sobre mutaciones genéticas en el moho Aspergillus Níger, desempeñó papel principal en la organización del primer congreso internacional de genética celebrado en Berlín en 1927; y Jimena Fernández de la Vega destaca en el primer tercio del siglo XX en genética del desarrollo en España ${ }^{6}$.

Las mujeres que colaboraron con William Bateson en Cambridge en sus experimentos sobre genética de plantas y animales — Wheldale es una de un grupo que superó la docena- siguen siendo estudiadas por Marsha Richmond. También las cristalógrafas británicas de rayos $\mathrm{X}$ participaron en la eclosión de esta técnica como herramienta para comprender la función de las moléculas biológicas a través de sus estructuras, de la disposición en el espacio de los átomos que las conformaban, grupos de expertas en los que científicas como Dorothy Hogkin y Kathleen Lonsdale comparten tiempo histórico con la microbióloga Marjorie Stephenson, pionera sucesora del bioquímico británico Frederic Gowland Hopkins. Como las especialistas en historia medieval y de la medicina han puesto de manifiesto tantas veces, buscar a las mujeres es encontrarlas, basados la búsqueda y el análisis de los resultados en otras miradas sobre el mundo natural y el artificial, sobre el aislamiento y la purificación de enzimas en el laboratorio tanto como sobre los métodos de cultivo celular y la cría de lepidópteros y sus mecanismos de reproducción ${ }^{7}$.

\section{Mujeres que hablan de sí: epistemología y autoridad}

Las mujeres comenzaron a hablar de sí mismas, a contar su propia historia, a medida que accedieron al territorio exclusivamente de hombres que había sido la 
profesión médica reglada y con formación universitaria ${ }^{8}$. Medicina y biología son las áreas en las que las mujeres comienzan a verse representadas de forma sesgada; unas, por la autoridad de sus colegas hombres con los que trabajan, que las ocultan siquiera temporalmente; otras, por el propio modo de saber. Cuando los valores de cada tiempo toman la forma de cuerpos de mujer, aquella pelvis femenina superior que daría paso al cráneo superior — masculino - explicaría tamaños de huesos ajustados a culturas y jerarquías sociales aparentemente sexuadas ${ }^{9}$. Los cuerpos y los saberes y las prácticas sobre ellos son los principales objetos de estudio del feminismo. Como las gónadas y las células germinales, óvulos, espermatozoides y sus componentes se analizan en la intersección entre biología y medicina. Han sido las preguntas formuladas para dar respuestas que contribuyeran a la salud de las mujeres las que se referían a eso precisamente, a su salud, la nuestra, como algo más que una vía para parir la autoridad sexuada ${ }^{10}$.

No obstante tanto recurso investigador e intelectual dedicado a la reubicación de las mujeres en el discurso de la historia de la ciencia, y pese a haber tenido muchas de ellas un protagonismo notable en la manufactura del saber biológico y sus prácticas, una de las razones de su ausencia en las narraciones históricas heroicas es que no lograron la autoridad que los hombres de su tiempo sí acumularon. En esos medios de creciente autoridad masculina que es el devenir de la historia moderna y contemporánea, las jerarquías sociales vierten en su visión del mundo y en la invención de sus sociedades las mismas jerarquías que adjudican a su propia función política, social y cultural. Así se construyen las jerarquías del mundo, las del natural también, el nombre clasificatorio de las especies y sus triángulos, poderosos reproductores de una autoridad que se ajustaría también a la campana de Gauss. Por ese mecanismo de autoría masculina, se entienden las dificultades, cuando no las barreras evidentes, desplegadas contra el acceso público de las mujeres a actividades profesionales fuera del mundo doméstico. Y por ese mecanismo también se entiende que el mundo natural así imaginado haya achacado a las mujeres estereotipos que han prevalecido tales como la naturaleza del desorden y la intuición femenina como actividades casi mágicas, cuando no de brujería, frente a la racionalidad lógicamente ordenada que se achacó al masculino y a sus certezas.

Se trata de mundos que en el caso de la biología condensan en la capacidad cautivadora de la molécula magistral de $\mathrm{ADN}$, que dirigiría la actividad celular como emperador en imperio; y que desarrollos posteriores de la biología de proteínas e hidratos de carbono han llegado a desafiar al ofrecer imágenes alternativas a esta de un mundo celular sometido a permanente regulación de su actividad en función de lo que ocurra fuera y dentro de la célula, de lo que se detecte más acá y más allá de la membrana celular; posiciones de equilibrio que se retroalimentan sin cesar con el fin de mantenerse ese equilibro, que no consiste en la cantidad absoluta sino relativa de los distintos componentes moleculares ${ }^{11}$. Esas interacciones que hacen a los seres vivos como son y como serán en sucesivos momentos de su biografía casan mejor con un discurso de inclusión, con la agencia de las mujeres en la producción del conocimiento, de la sociedad y de sus estructuras.

\section{El género como agente}

Esa agencia femenina ha contribuido a las críticas al relato histórico de acumulación y desarrollo de las ciencias desde la 
revolución industrial que se producen desde la década de 1970. Como uno de los movimientos sociales más influyentes en el pensamiento contemporáneo, el feminismo y su participación en los análisis de las ciencias - los estudios de ciencia y género- han hecho aportaciones y siguen haciéndolo a los estudios sobre historia de la biología. Junto a los trabajos sobre biólogas ilustres invisibles en la reconstrucción tradicional, emergen otros sobre el concepto de sexo biológico, reproducción sexual y hormonas, por mencionar sólo algunos de los que resultaron influyentes en el pensamiento sobre feminismo y biología. Los cuerpos y las sociedades clasificados en dos grupos, de hombres y mujeres, reproducen las formas dicotómicas de la cultura de nuestro tiempo y han generado conocimientos médicos y biológicos androcéntricos que prevalecen en las culturas y en las prácticas médicas ${ }^{12}$.

A lo largo del último siglo y medio, por ceñirnos a la época a la que se refiere el conjunto de libros que se están mencionando aquí, el curso de las investigaciones y el pensamiento biológico han sexuado la vida y la sociedad, sus culturas y costumbres. De ese partir en dos el mundo surgen las sociedades en las que el sexo de los seres es un valor esencial para la clasificación y las jerarquías sociales. En esta nuestra humanidad contemporánea, las mujeres han - hemos- encontrado huecos que se hicieron espacios de presentación y representación del mundo; espacios que han permitido ampliar aquel que los hombres generaron en las universidades, en las prácticas de laboratorio y en el pensamiento científico del mundo moderno. La visión occidental contemporánea se muestra sobrecargada de sesgos y el del sexo y el género son dos de los más elocuentes. Debido a la discriminación de las mujeres, disuadidas de aparecer como autoridad académica y social, diluida y absorbida en las perso- nalidades de científicos con los que trabajaban - parejas sentimentales, hermanos, padres - el repaso superficial de las historias tradicionales de las ciencias solía dejarlas ausentes.

Los libros de Ruth Hubbard, Helen Longino, Londa Schiebinger y tantas otras abrieron un camino que no ha hecho más que ramificarse y desarrollarse desde entonces ${ }^{13}$. Adele Clarke, Anne Fausto-Sterling y Nelly Oudshoorn son parte de esa influencia ${ }^{14}$. Los trabajos de estas investigadoras son buenos puntos de partida de cualquier investigación sobre el género en los hallazgos y los recursos narrativos de la biología contemporánea. El trabajo sobre hormonas, su papel fisiológico y su función en el diseño de anticonceptivos orales muestran no sólo el papel de las mujeres en el desarrollo de estos productos de la fisiología animal, sino la influencia que las necesidades expresadas por algunas de ellas tuvieron en las investigaciones dirigidas a obtener y poner en el mercado productos destinados a evitar embarazos tras las relaciones sexuales ${ }^{15}$. Los estudios sobre el sexo y el género, ambos como un producto cultural y no solo biológico, se convirtieron en uno de los más eficaces conjuntos de propuestas en la articulación de los trabajos de epistemología feminista.

La presencia sistemática de mujeres entre especialistas en ciencias experimentales, sociales y humanas devuelve la sabiduría de las mujeres y sus permanentes ambiciones personales, intelectuales, profesionales y científicas. En este mundo de hoy, del que Teresa Ortiz dice que cuenta con más de un siglo de estudios sobre medicina, historia y género, muchos de los libros de historia de la biología, de las ideas biológicas y biomédicas incorporan a las mujeres como agentes principales de la sucesión de eventos que analizan ${ }^{16}$. Véase por ejemplo el precioso capítulo que Theodore Porter (2004) 
dedica al Club de Hombres y Mujeres que el estadístico y pionero de la biometría Karl Pearson fundó en 1885. La propuesta de Porter de sumergir a Pearson en, entre otros procesos, el de sus relaciones con las mujeres y las ideas que sobre ello tenía introducen a éstas en su relato histórico y biográfico: Porter las recupera como agentes en la trayectoria intelectual y profesional de Pearson. Tras arrebatos de objetividad que escondían de forma sistemática cualquier emoción afectiva, Porter presenta por fin a un Pearson que logra hablar de sentimientos con las mujeres y logra aceptar y negociar un espacio emocional a compartir con Maria Sharpe, que se convierte en actriz principal de su vida y que pese a sus intereses intelectuales, finalmente atiende a su papel de esposa y madre, sujeta a las mismas normas que compartían mujeres inquietas y activas de la era post-victoriana, que como ella leían Casa de muñecas, de Ibsen y estudiaban noruego. Y el propio Pearson pudo entonces sentir el reclamo de aquellas mujeres que querían reconciliar la maternidad con la autonomía personal ${ }^{17}$. Leer a Porter y ver de qué forma da voz a las mujeres en su historia de Pearson sugiere que la inclusión de las mujeres como agentes de las historias, la de las ciencias y la de las sociedades, es ambición posible, que ensancha visiones de los mundos en los que los saberes y las prácticas generadoras de autoridad son mundos de gentes de distinto sexo cuyas emociones intervienen, la intervención de las cuales puede hacerse explícita, al admitirla con la reflexividad comparable a la de quien se implica en el estudio de esas culturas desde un lugar y un momento concretos.

El asunto de la dicotomía personal/intelectual evoca otras dicotomías que consagran sesgos sociales y sexistas, y que como las clasificaciones entre masculino y femenino, no sólo de sexo sino también de género, han estabilizado, siquiera temporalmente, las desigualdades. También sugiere un paisaje de mujeres que han contado con hombres para vivir y encontrar espacios de vida intelectual y actividad social y profesional autónomas. Ambientes preocupados por las desigualdades han favorecido en algunos momentos esas actividades de mujeres en mundos gobernados por hombres ${ }^{18}$.

Y, mientras tanto, la historia de las mujeres nos ha enseñado que no hay un aumento permanentemente creciente de la consideración y el respeto a la participación de las mujeres y a su inclusión en la vida fuera del hogar. De ese mundo de clubes modernos por la igualdad entre los sexos como el de Pearson no se traza una línea ascendente hasta la actualidad. El siglo XX aparece desde sus inicios plagado de sesgos que algunas mujeres han analizado. Y de quiebras de tendencias que parecían prometedoras.

\section{Algunos libros recientes: Ilana Löwy, Teresa Ortiz, Isabel Delgado}

La historia política y cultural de Occidente modela las personalidades de forma recíproca a como cada cual interacciona y condiciona su propio tiempo. Las feministas se han tomado el suyo desde el sufragismo. Pero como no hay un único feminismo sino varios y debates intensos entre ellos, tampoco todas las feministas comparten procedencia y pertenencia social y cultural. Cuando Ilana Löwy (2006) relata los problemas de la desigualdad entre hombres y mujeres, y da cuenta de paso, o por cierto, de su propia identidad, construye de modo propiamente cultural y feminista su propio saber de forma reflexiva: se incluye como agente de los saberes a los que se refiere y se pregunta sobre ellos haciendo explícita su fisionomía y una condición cultural heredadas. El repaso general a los te- 
mas que explora están cargados de emoción, y de intención integradora contra, dice, toda discriminación inaceptable. De los aspectos estéticos - los cuerpos de las mujeres y la publicidad y las jerarquías de género - al cuerpo hormonal que ha molecularizado - también - la menopausia, Ilana Löwy se traslada a los aspectos profesionales de autoridad y género y a la opción de las relaciones heterosexuales y su relación con esas jerarquías de género ${ }^{19}$.

El cuerpo sexuado a la vista ha sido modelo y contramodelo de belleza, de pasión y descrédito, según épocas y lugares, con formas y componentes - físicos y culturales - que permiten clasificaciones temporales y geográficas. Los de las mujeres llegan a adoptar la forma del corsé en el que parecían recluirse por propia voluntad, como sugiere Londa Schiebinger en sus estudios sobre esqueletos y anatomía de las mujeres en la Ilustración ${ }^{20}$. Hay un proyecto intelectual que es social y emotivo en las páginas que traza Ilana Löwy cuando, para terminar, propone los aspectos vitales más cotidianos que debilitarían las pautas de dominación masculina y sugiere que no hay soluciones mágicas ni atajos para neutralizar su enorme capacidad de regeneración.

El libro de Teresa Ortiz es también vital, recorrido para una biografía de los estudios sobre mujeres, salud e historia feminista de la medicina. Tras su aspecto de edición amable y modesta - es un libro de tamaño pequeño que recuerda el formato de manuales guía para servicios religiosos - están algunas de las páginas más ricas que se han dedicado últimamente en español a trazar el desarrollo de los estudios sobre género y medicina. Como experta pionera en nuestro país en estos temas, ha contribuido a la trayectoria vital de este tipo de estudios. Teresa Ortiz ha escarbado en la historiografía y ha recreado la historia del feminismo académico para llegar al estado actual de la cuestión. Recorre sucesivas olas de la historiografía feminista de la medicina, las conceptualizaciones -mujer, sexo, género- y las herramientas que ha manejado, fuentes y perspectivas que han llevado al análisis de las fuentes mismas, sujetas a un escrutinio similar el que se sometían los agravios y las discriminaciones que están en el origen de los estudios mismos sobre mujeres, medicina y salud. Sus propuestas para una genealogía sitúan a los estudios sobre mujeres y medicina junto a las mujeres mismas y a su reconocimiento como agentes en historia de la medicina y de la salud de las mujeres, como mujeres médicas, sanadoras que se constituyen en agencia al estudiarse a sí mismas y a sus predecesoras. Como observadora y activista académica del proceso en el que se ha especializado de participación de las mujeres en la medicina, en la historia de la medicina y en la historiografía feminista de ambas, medicina y salud de las mujeres, no levanta fronteras sino que las atraviesa y sugiere así una interdisciplinariedad de la que su propio libro es portador. El resultado es un manual completo para extender el conocimiento sobre mujeres y salud en la historia de la medicina para cualquier persona que pretenda situarse en todos esos aspectos y comprender las relaciones entre ellos.

Los efectos del androcentrismo se manifiestan en muchos espacios del saber biológico, y no solo en las hormonas, así como en muchos de los criterios sobre la salud de las mujeres. Los descubrimientos de los cromosomas y adjudicar a estos sexo y género de forma que el modelo de hembras sea XX y el de machos XY es, como dice Isabel Delgado (2007), limitado y poco prometedor, pues esos modelos parejos han llevado a la identificación del cromosoma Y con lo masculino, «uno de los elementos más claros del androcentrismo presente en las investiga- 
ciones biológicas sobre el sexo», según esta autora. En la historia de los cromosomas sexuales que relata Isabel Delgado, muchas mujeres hicieron contribuciones significativas, entre ellas, se refiere a Nettie Stevens como una de las más innovadoras, hasta hace poco oculta tras E. B. Wilson, quien solía llevarse todo el crédito por el descubrimiento de los cromosomas. Delgado muestra cómo las investigaciones sobre el sexo han tenido un papel central en la producción de conocimiento biológico entre finales del siglo XIX y las primeras décadas del xx; y sugiere que la biología incorpora los valores de su tiempo para terminar por condensar en la teoría cromosómica del sexo las investigaciones previas en embriología y citología principalmente pero también de otras como la zoología, la agricultura y la cría de animales. Inspirada en las aportaciones fundamentales de Nettie Stevens, Delgado ha buscado a las mujeres que habían investigado los cromosomas y ha encontrado a muchas, y las ha devuelto al primer plano de la historia de la biología contemporánea. A través del análisis de los trabajos de éstas y de sus pares hombres, esta autora da testimonio de la incorporación de las culturas sexistas a la narrativa científica sobre estos devenidos potentes orgánulos del núcleo celular ${ }^{21}$. Las investigaciones detalladas que sostienen las propuestas de aproximación a la biología y a la sociedad contemporáneas que hace Isabel Delgado sugieren que el determinismo genético es uno de los valores de nuestro tiempo pero no la única explicación posible del desarrollo biológico, sexuado o no.

\section{Para concluir}

De las autoras mencionadas y de muchas otras se extraen las bases para un pensamiento que tomaría en cuenta intuiciones sobre los sesgos de saberes y prácticas experimentales que consolidaban las desigualdades, en este caso entre los sexos. Más allá, o más acá, de las barreras institucionales, sus prácticas investigadoras detalladas y documentadas muestras los sesgos del conocimiento mismo. En pleno momento innovador en los estudios sobre las ciencias como fueron los años ochenta para el desarrollo de los estudios denominados culturales y sociales, el cuestionamiento de las verdades de la biología como conocimiento neutro constituye uno de los más fecundos puntos de partida de los estudios feministas sobre la biología. Con esa mirada observadora de mujeres conscientes de los prejuicios que generan e incorporan las culturas de su tiempo, se leen los manuales, las publicaciones y los hitos de la biomedicina de forma que es muy difícil no darse cuenta del modo estrechamente entrelazado en el que las ciencias y las culturas de las sociedades se construyen y modelan, mutua y permanentemente, de manera que unas y otras se reproducen por cruzamientos en los que se intercambias culturas jerárquicas, clasificatorias y de orden social.

\section{NOTAS}

\footnotetext{
1 Teresa Ortiz ha seguido la trayectoria de los grupos de investigación feministas devenidos institutos y departamentos de estudios sobre las mujeres. Entre sus primeros libros publicados con información completa sobre este asunto en colaboración con otras investigadoras véanse T. Ortiz, Johanna Birriel y Vicen-
}

ta Marín, Universidad y feminismo en España I. Bibliografia de Estudios de las mujeres, Granada, Editorial Universidad, 1998; y ibid. (1999), II. Situación de los estudios de las mujeres en las universidades españolas en los años 90, Granada, Editorial Universidad. Para estudios similares véase también Pilar Ballarín, 
M. Teresa Gallego e Isabel Martínez, Los estudios de las mujeres en las universidades española 1975-1995. Libro Blanco, Madrid, Instituto de la Mujer, 1995.

2 Sobre las científicas en España, véase Eulalia Pérez Sedeño (ed.), Las mujeres en el sistema español de ciencia y tecnología, Madrid, OEI, 2001; Paloma Alcalá, Eulalia Pérez Sedeño y M. J. Santesmases, Mujer y ciencia: la situación de las mujeres investigadoras en España, Madrid, FECYT, 2005.

3 Margaret Rossiter, Women Scientist in America: Struggles and Strategies to 1940, Baltimore: The Johns Hopkins University Press, 1982. Pnina G. Abir-Am y Dorinda Outram (eds.), Uneasy Careers and Intimate Lives: Women in Science, 1789-1979, New Brunswick, Rutgers University Press, 1987. Kass-Simon and Patricia Farnes (eds.), Women of Science: Righting the Record (Bloomington: Indiana University Press, 1990. Margaret Rossiter, Women Scientist in America: Before the Affirmative Action 1940-1972, Baltimore: The Johns Hopkins University Press, 1995. Teresa Ortiz Gómez y Gloria Becerra Conde (eds.), Mujeres de ciencias: Mujer, feminismo y ciencias naturales, experimentales y tecnológicas, Granada, Universidad de Granada, 1996. Teresa Ortiz Gómez, «La mujer como profesional de la medicina en la España contemporánea: El caso de Andalucía (1898-1981)», Dynamis, 5-6, 343-366, 1985-86. Puede verse también M. J. Santesmases, Cientificas en España: profesionalización y modernización social, Madrid, Instituto de la Mujer, 2000.

${ }^{4}$ Montserrat Cabré y Teresa Ortiz (eds.), Sanadoras, matronas y médicas en Europa, Barcelona: Icaria, 2001 que es la reedición de un número monográfico de Dynamis con título similar, Mujeres y salud. Prácticas y saberes y para la que se tradujeron los artículos inicialmente publicados en otras lenguas. El esfuerzo por traducir libros introductorios e influyentes sobre ciencias y género ha tenido la virtud de ampliar los grupos interesados.

5 Margaret Derry, Bred for perfection. Shorthorn cattle, collies, and Arabian horses since 1800, Baltimore-Londres, Johns Hopkins University Press, 2003.

6 Sobre Jimena Fernández de la Vega, véase Isabel Delgado, Los cromosomas sexuales, Madrid, CSIC, 2007. Sobre las genetistas extranjeras mencionadas, véanse Jean Maienschein, «What determines sex? A study of converging approaches, 1880-1916», Isis, 75: 457-480, 1984, que es uno de los primeros trabajos sobre Nettie Stevens y Marilyn Bailey Ogilvie, «Inbreeding, eugenics and Helen Dean King», Journal of the History of Biology 40: 467-507, 2007; Marsha L. Richmond, «Muriel Wheldale Onslow and early biochemical genetics», Journal of the History of Biology, 40: 389-426, 2007; Ida H. Stamhuis y Arve Monsen, «Kristine Bonnevie, Tina Tammes and Elisabeth Schiemann in early genetics: emerging chances for a university career for women», Journal of the History of Biology, 40: 427-466, 2007; todos estos artículos forman parte de una sección especial dedicada a las mujeres en la genética publicados en un número reciente del JHB.

7 Monica Green, «En busca de una "auténtica" medicina de mujeres: los extraños destinos de Trota de Salerno e Hildegarda de Bingen", en Montserrat Cabré y Teresa Ortiz (eds.) Sanadoras, matronas y médicas en Europa, siglos xii-xx, Barcelona, Icaria, 2001. Entre las biografías de algunas científicas mencionadas, véanse Georgina Ferry, Dorothy Hodgkin, a life, Londres, Granta books, 1998; Evelyn Fox Keller, Seducida por lo vivo. Vida y obra de Bárbara McClintock, Barcelona, Fontalba, 1984, así como las dos biografías de Rosalind Franklin, Brenda Maddox, Rosalind Franklin: The dark lady of DNA, Nueva Cork, HarperCollins, 2002, y Anne Sayre, Rosalind Franklin y el $A D N$, Madrid, horas y Horas, trad. Teresa Carretero, 1997(1975).

${ }^{8}$ Un caso interesante es el de Rosalyn Yalow. Física de formación, trabajó en medicina en el sistema inmune como un problema de biología experimental mientras aprovechaba las oportunidades que brindaban los presupuestos disponibles en los orígenes de la medicina nuclear, de la que fue pionera. Recibió el premio Nobel de Medicina por su invención con Solomon Berson de los radioinmunoensayos. En su autobiografía Nobel menciona, cosa muy inusual, a sus hijos - ella habla de su hija, quien asiste a la ceremonia, dijo, acompañada de su marido y ambos que estaban con ella y su propio marido en su luna de miel-. Véase http://nobelprize.org/nobel_prizes/medicine/ laureates/1977/yalow-autobio.html así como Eugene Straus, Rosalyn Yalow. Her life and work in medicine, Nueva York, Basic books, 1998.

9 Londa Schiebinger, «More than skin deep: The scientific search for sexual differences», en su The Mind has no Sex? Women in the Origins of Modern Science, Cambridge, MA: Harvard University Press, 1989; versión española de María Condor, Madrid, Cátedra, 2004.

10 La compilación de Angela Creager, Elizabeth Lunbeck y Londa Schiebinger (eds.), Feminism in twentieth century science, technology and medicine, Chicago, University of Chicago Press, 2001, escoge varios textos referentes a biología del desarrollo, primatología, cuerpos y mentes, virus y epidemias que sugieren raíces cruzadas de los estudios feministas sobre biología y sobre medicina.

11 Las críticas a la magistralidad del ADN desde los estudios sociales y también los culturales de la ciencia han sido hechas por mujeres: véase Dorothy, Nelkin y M. Susan Lindee, The DNA mistique. The gene as a cultural icon, Nueva York, Freeman, 1995. Sobre las prácticas de la biología del siglo Xx y sus culturas, véase la compilación de Adele E. Clarke y Joan Fujimura (eds.), The Right Tools for the Job: At Work in Twentieth-Century Life Sciences, Princeton, N.J., Princeton University Press, 1992.

12 El grupo Genciana de la Universidad de Zaragoza es probablemente el más activo en España en estos 
asuntos del androcentrismo del conocimiento médico. Véanse, entre otros, Consuelo Miqueo, C. Tomás, C. Tejero, María José Barral, Teresa Fernández y T. Yago (eds.), Perspectiva de genero en salud. Fundamentos cientificos y socioprofesionales de diferencias sexuales no previstas, Madrid, Minerva, 2001; y María José Barral, Carmen Magallón, C. Miqueo y D. Sánchez (eds.), Interacciones ciencia y género: discursos y prácticas científicas de mujeres, Barcelona, Icaria-Antrazyt, 1999.

13 De entre los de Hubbard, está su famoso The Politics of Women's Biology, New Brunswick: Rutgers, 1990. Pero sus trabajos previos abrieron debates que siguen vivos, como sus investigaciones sobre las mujeres en la teoría de la evolución, en su artículo «Have only men evolved?», en Ruth Hubbard, Mary Sue Henifin y Barbara Fried (eds.), Women looking at biology looking at women, Cambridge, Mass., Schenkman, 1979; y los asuntos planteados en el libro que editó con Marian Lowe también en 1979, Genes and Gender II: Pitfalls in research on sex and gender, Staten Island, Gordian Press.

14 Me refiero especialmente a Adele Clarke, Disciplining reproduction: modernity, American life and the "problem of sex», Berkeley, University of California Press, 1998; Anne Fausto-Sterling, Sexing the body. Gender politics and the construction of sexuality, Nueva York: Basic Books, 2000; Marianne van den Wijngaard, Reinventing the sexes: the biomedical construction of femininity and masculinity, Bloomington, Indiana, Indiana University Press, 1997; y Nelly Oudshoorn, Beyond the Natural Body: an archaeology of sex hormones, Londres-Nueva York, Routledge, 1994. Helen Longino, Una contribución sobre España está en Richard Cleminson y Rosa Medina Doménech, «¿Mujer u hombre? Hermafroditismo, tecnologías médicas e identificación del sexo en España, 18601925», Dynamis, 24: 53-91, 2004.

15 Lara Marks, Sexual chemistry. A history of the contraceptive pill, New Haven-Londres, Yale University Press, 2001; Adele Clarke, Disciplining reproduction: modernity, American life and the «problem of sex», Berkeley, University of California Press, 1998. Véanse también las contribuciones a la historia de la genética de Diane Paul, The politics of heredity: essays on eugenics, biomedicine and the nature-nurture debate Albany, Nueva York, State University of New York, 1998, y Controlling human heredity: 1865 to the present Nueva York, Humanity Books.

16 Teresa Ortiz, Medicina, historia y género: 130 años de investigación feminista, Oviedo, KRK, 2006.

17 Theodore M. Porter, Karl Pearson: the scientific life in a statistical age, Princeton-Oxford, Princeton University Press, 2004.

18 Es el caso, ya mencionado, de las cristalógrafas de rayos $\mathrm{X}$ que desarrollaron sus trabajos en un grupo inicialmente liderado por John Desmond Bernal, véase el libro ya citado de Georgina Ferry sobre Dorothy Hodgkin. También con este argumento, entre otros, explica María Rentetzi la presencia de mujeres especialistas en el Instituto de la Radioactividad de Viena; véanse su «Gender, Politics and Radioactivity Research in Interwar Vienna: The Case of the Institute for Radium Research», Isis, 95, 2004, 359-93 así como su libro Trafficking materials and gendered experimental practices: Radium research in 20th century Viena, Columbia University Press, disponible en Internet en http://www.gutenberg-e.org/rentetzi/..

19 Ilana Löwy, L'emprise du genre. Masculinité, féminité, inégalité, Paris, La Dispute, 2006.

20 Londa Schiebinger, «More than skin deep: The scientific search for sexual differences», en su The Mind has no Sex? Women in the Origins of Modern Science, Cambridge, MA, Harvard University Press, 1989; versión española de María Condor, Madrid, Cátedra, 2004.

21 Isabel Delgado, Los cromosomas sexuales, Madrid, CSIC, 2007. Su trabajo evoca los de Marsha Richmond, véase (2006): "The "Domestication" of Heredity: The Familial Organisation of Geneticists at Cambridge University, 1895-1910», Journal of the History of Biology 39: 565-605; y también los de Helga Satzinger sobre los Boveri, véase el de 2005, «The Chromosomal Theory of Heredity and the Problem of Gender Equality», en A Cultural History of Heredity III: $19^{\text {th }}$ and early $20^{\text {th }}$ centuries, Max-Planck-Institut für Wissenschaftsgeschichte, Preprint 294, 101-114. 